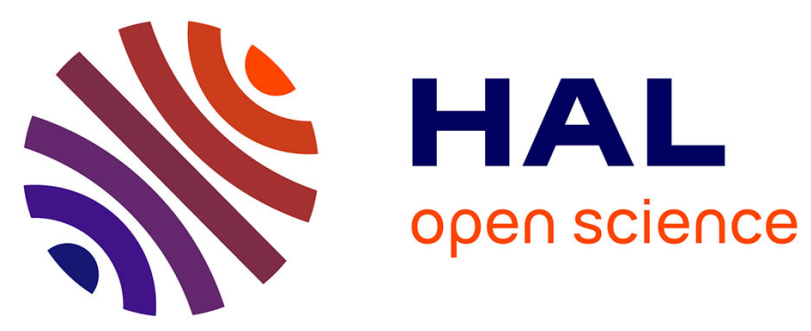

\title{
Layout Design by Integration of Multi-agent Based Simulation and Optimization
}

Nobutada Fujii, Toshiya Kaihara, Tomomi Nonaka, Shun Nogami

\section{To cite this version:}

Nobutada Fujii, Toshiya Kaihara, Tomomi Nonaka, Shun Nogami. Layout Design by Integration of Multi-agent Based Simulation and Optimization. IFIP International Conference on Advances in Production Management Systems (APMS), Sep 2014, Ajaccio, France. pp.375-382, 10.1007/978-3662-44733-8_47. hal-01387275

\section{HAL Id: hal-01387275 \\ https://hal.inria.fr/hal-01387275}

Submitted on 25 Oct 2016

HAL is a multi-disciplinary open access archive for the deposit and dissemination of scientific research documents, whether they are published or not. The documents may come from teaching and research institutions in France or abroad, or from public or private research centers.
L'archive ouverte pluridisciplinaire $\mathbf{H A L}$, est destinée au dépôt et à la diffusion de documents scientifiques de niveau recherche, publiés ou non, émanant des établissements d'enseignement et de recherche français ou étrangers, des laboratoires publics ou privés.

\section{(c)(1)}

Distributed under a Creative Commons Attribution| 4.0 International License 


\title{
Layout Design by Integration of Multi-agent based Simulation and Optimization
}

\section{- Application to Underground Shopping Streets -}

\author{
Nobutada Fujii $^{1 *}$, Toshiya Kaihara ${ }^{1}$, Tomomi Nonaka ${ }^{2}$ and Shun Nogami ${ }^{1}$ \\ ${ }^{1}$ Graduate School of System Informatics, Kobe University \\ Rokkodai 1-1, Nada, Kobe 657-8501, Japan \\ ${ }^{2}$ Dept. of Industrial and Systems Engineering, Aoyama Gakuin University, Kanagawa, Japan \\ nfujii@phoenix.kobe-u.ac.jp
}

\begin{abstract}
This paper proposes a layout design method by integration of multiagent based simulation and optimization. The proposed method adopts 'optimization for simulation' approach to integrate simulation and optimization, in which optimization is executed first, then the result is evaluated through simulation by various scenarios. The optimization is repeated sequentially using an output data derived by the simulation executed in each previous turn. The proposed method is applied to a layout design problem for underground shopping streets, which is the problem determines store positions to be located. The objective of the layout design is to arrange store positions attractively for passers considering their preferences and target directions, which depend on the day of the week, time zones and seasons. Computer experiments are conducted to confirm the effectiveness of the proposed method.
\end{abstract}

Keywords: multi-agent based simulation, optimization, layout design, service engineering

\section{Introduction}

Layout design for production systems and social systems is difficult to achieve both high levels of productivity and low cost simultaneously. Layout design methods have been proposed, however, most of them were implemented based on heuristic approaches to obtain better solutions without ensuring their optimality [1]. One of the most popular and practical methods is 'SLP (Systematic Layout Planning)' proposed by Muther [2]. A procedure of the SLP is as follows; (1) relationship between facilities based on their material flows by 'from-to charts' is revealed. (2) A chart named 'activity relationship chart' is developed based on the activities. (3) A required space is measured for each facility, and (4) a space relationship diagram is constructed by combining the activity relationship chart and the space requirement. (5) Alternative plans are developed to consider other remaining constraints. Finally, (6) a suitable layout plan is selected from the alternatives. The SLP method has been often implemented for the layout design of real plants and facilities, however, it is hard to devel-

adfa, p. 1, 2011.

(C) Springer-Verlag Berlin Heidelberg 2011 
op the 'activity relationship chart' using the 'from-to chart' to describe a material flow because of the huge combinations for the large scale problem.

Layout planning methods based on mathematical programming have been also proposed, in which the layout problem has been formulated as the quadratic assignment problems in the area of OR [3]. Recent developments of meta-heuristic approaches realize to solve a relatively large-scale optimization problem efficiently. In particular, many studies implement evolutionally computation-based optimization methods have been proposed [4][5]. The meta-heuristic based approaches enable to solve the real scale problems, however, it is usually required to set the static objective function such as fixed varieties of items or unchangeable available facilities in order to solve the facility layout planning within the framework of combinatorial optimization problem. Hence, the approaches should be extended to adapt current situations including dynamic and daily changes of production items and facility changes.

Simulation based approaches have been also proposed in order to consider probabilistic behaviors in systems or events which are difficult to be formulated. The approaches have no optimization logics, so that it is hard to change an experimental condition by using the simulation results. The simulation-based approaches can evaluate only predetermined layout plans. It should be demonstrated try and error processes to evaluate which plan is the best solution.

To overcome above mentioned limitations, integration methods of simulation based approach and optimization have been proposed [6][7]. The simulation and optimization are repeatedly executed; the obtained results derived from one method are incorporated into the other method as the input data. The simulation and optimization are implemented in a mutually complementary manner. In this paper, a layout design method by integrating multi-agent based simulation and optimization is proposed. To integrate the simulation and optimization, an approach of 'optimization for simulation' is implemented; the approach evaluates alternative plans by employing simulation, then optimization is executed by using the simulation results. The proposed method is applied to a social system layout design problem: underground shopping streets, in which the layout design problem is to determine the store positions to be located in the underground shopping streets. The layout design is implemented to arrange attractive stores for passers considering their preferences and target directions changing due to the situation such as the day of the week, time zones and seasons. The objective function of the optimization is to maximize total utilities for each store. The optimization and simulation are sequentially repeated using an output data derived by the simulation executed in each previous turn.

In the remainder of this paper will describe the framework of integration of multi-agent simulation and optimization in the section 2 . Then, the application method of the framework to the layout design problem for underground shopping streets will be described in the section 3 . In the section 4 , computer experiments are conducted to confirm the feasibilities of the proposed method by comparing the current layout and the obtained layout by the proposed method. Finally, the conclusion and future works will be described in the section 5 . 


\section{Framework of Integration of Simulation and Optimization}

There are two purposes to integrate simulation and optimization [7]. The first one is to evaluate an alternative plan on simulation, then process optimization using the results by the simulation. In this approach, simulation is mainly demonstrated rather than optimization so that which is named 'Optimization for Simulation'. In the second one, optimization is demonstrated mainly and it is named 'Simulation for Optimization'. Optimization results are evaluated through simulations by scenario analysis. In this paper, the approach of 'Optimization for Simulation' is employed for a layout design method. Figure 1 shows the proposed framework of integration of multi-agent based simulation and optimization.

Multi-agent based simulation models components existing in the targeted system as agents and the system executes simulation as a distributed autonomous system. The agent can represent the model of either artifact or human in the simulation; it is relatively easy to introduce human objects into the simulation. Since human factor still plays important role in manufacturing systems as well as service production systems, human interventions have possibilities to enhance service quality or may influence on productivity. Furthermore, flows of products and humans in production and service systems are complex so that it is difficult to develop a complete model for mathematical programming. Therefore, it should be required to consider temporal influences derived by the product and human flows throughout spatial design of layout planning. Most of earlier studies in the area of OR, above mentioned temporal factors have been incorporated into the models by a simplified way with abstraction. Hence, the proposed approach by the integration of multi-agent simulation is expected to develop a layout planning method considering both products flows and human ones: spatial and temporal factors.

In addition, it is needed a large amount of computation time in order to implement high simulation accuracy when demonstrated by integration of optimization and simulation. To balance a tradeoff between accuracy and length of computation time, it is required to apply any solutions. In this paper, a solution to solve the tradeoff is incorporated into the proposed model, and it will be described in the following section.

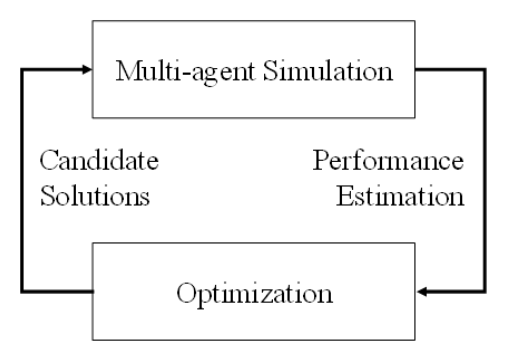

Fig. 1. Framework of Integration of Multi-agent based Simulation and Optimization 


\section{$3 \quad$ Layout Design for Underground Shopping Streets}

\subsection{Outline of the proposed method}

An underground shopping street is something familiar with people's daily life in particular in urban areas. Recently passers who just want to go through the underground shopping streets as the passageway without any specific purpose for shopping or browsing are increasing. Competitions between stores located on the underground shopping streets and other stores located above ground have been growing. In general, customers can be categorized into two segments of planning purchases and nonplanning purchases. This study targets the passers who just go through the underground shopping streets, so that increasing non-planning purchases of the passers is selected for the main evaluation criterion.

An earlier study showed the effectiveness of layout planning for retail stores targeted non-planning purchases as well as planning purchases [8]. In the layout design of the underground shopping streets, it is needed to consider specific characteristics of the underground shopping streets, which differ from general store layout problems; there are many entrances and exits and each passer has own target direction in the underground shopping streets. How passers select passing ways vary according to the passers' purposes and that are frequently changed depending on the situations such as day of the week, time zone and season's factor. Hence a store layout design should be implemented to arrange attractive stores effectively considering changing passers behaviors.

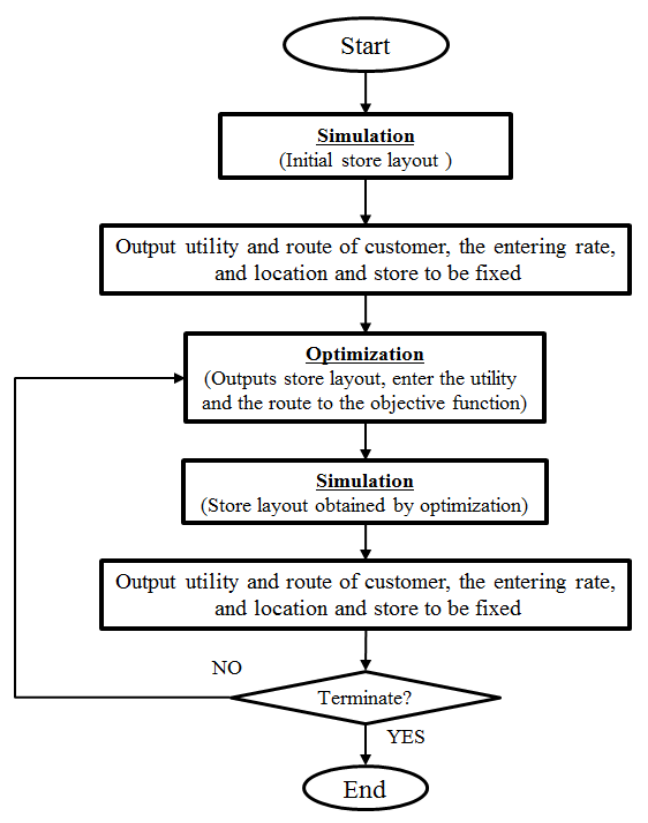

Fig. 2. Flowchart of the Layout Design of Shopping Street 
Figure 2 shows the flowchart of the layout design of shopping street. The proposed method integrates multi-agent based simulation and optimization. Once a layout design is implemented, customers' migration paths will be changed according to the derived layout. The layout design is required to evaluate sequentially by repeating simulation and optimization. As a result, a large amount of computation time is needed. The proposed model implements sequential processing of simulation and optimization through fixing store's position partially to be incorporated into the repeating processes. Therefore, the optimizations are executed considering changing consumers' behaviors simultaneously and it enables to arrange attractive stores to improve total customer traffic rates for the underground overall shopping streets.

\subsection{Algorithm of the proposed method}

A flow chart of the layout design of shopping street is shown in Figure 2. Simulation and optimization are integrated and implemented to repeat in order to develop a layout gradually.

The purpose of the algorithm is to develop a layout design to let passers nonplanning purchase. An objective function is to maximize total utilities of arranged stores. The objective function $f$ is to determine where store $j$ to be located in assignment place $k$, which is formulated as follows;

$$
\begin{gathered}
\text { maximize } f=\sum_{i=1}^{I} g_{i} \\
g_{i}=\left\{\begin{array}{c}
\frac{\sum_{j=1}^{J} \sum_{k=1}^{K} \max \left\{\left(U_{i j}-T_{i}\right), 0\right\} \cdot x_{i k} \cdot y_{j k}}{m_{i}} \\
\left.0 \quad \text { if } m_{i}=0\right)
\end{array}\right.
\end{gathered}
$$

subject to

$$
\begin{gathered}
\text { fix }_{l j k}=\{0,1\} \quad(\text { for all } l, j, k) \\
\sum_{j=1}^{J} \sum_{k=1}^{K} \text { fix }_{l j k}=1 \quad(\text { for all } l) \\
\sum_{k=1}^{K} y_{j k}=1(\text { for all } j) \\
\sum_{j=1}^{J} y_{j k}=1(\text { for all } k) \\
x_{i k}=\{0,1\} \quad(\text { for all } i, k) \\
y_{j k}=\{0,1\}\left\{j, k \mid \sum_{l=1}^{L} \text { fix }_{l j k}=0\right\}
\end{gathered}
$$

Constraints are formulated as from Equation (3) to (8). In the decision variable (3), $f i x_{l j k}=1$ means that store $j$ is arranged at place $k$ in simulation turn $l$, otherwise $f i x_{l j k}=0$. The Equation (4) indicates that only one store is arranged at a place in each turn of the simulation. The constraint determines that a store is arranged at one place is shown in Equation (5). All places must be assigned any store shown in Equa- 
tion (6). The decision variable Equation (7) represents $x_{i k}=1$ means that customer $i$ pass through along place $k$, otherwise $x_{i k}=0$. Equation (8) indicates that $y_{j k}=1$ means the store $j$ is arranged at place $k$, which has not been assigned, otherwise $y_{j k}=$ 0 . The parameter $m_{i}$ represents the total number of stores to be passed through by consumer $i$.

First of all, the simulation with the initial (current) layout is executed. The simulation derives the utility $U_{i j}$ of customer $i$ toward store $j$ and the threshold values of $T_{i}$, $f i x_{l j k}, x_{i k}, m_{i}$ to determine whether customer $i$ enters store $j$ or not. Then the optimization is executed using the above mentioned utilities and threshold values as input data by the decision variable $y_{j k}$ to maximize the objective function value.

\section{Computer Experiments}

The target area represents the underground shopping street where 24 stores and 8 exits are located. The number of passenger is assumed 15,000. Figure 3 illustrates the current layout of the shopping street and that is modeled in $1 / 4$ scale of the actual shopping street in this paper. The number of passers is calculated by using the decreasing ratio of the area space [9]. The exits along four dimensions are set neighboring four different facilities located on the ground. The left-hand side is located along station, the bottom side is located along department store, the right side is located along offices and the upper side is located along downtown, respectively. The assumption is set that business persons tend to prefer the station and office sides, housewives prefer the station and department store sides and students tend to move between the station and downtown sides. The located stores are categorized into three groups of restaurant, variety and clothing shop.

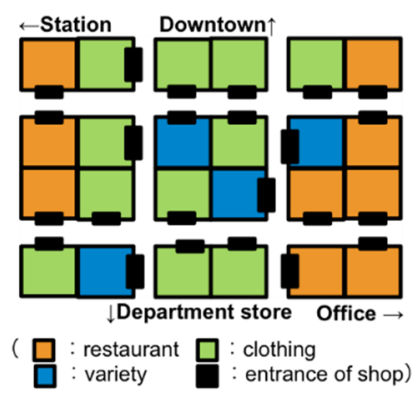

Fig. 3. Current layout of shopping street 


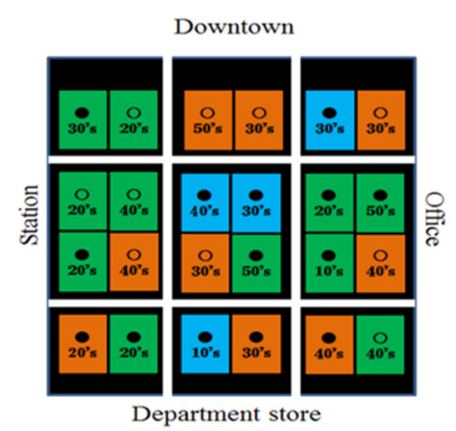

Fig. 4. Obtained layout by the proposed model

Table 1. Comparison results between current and the proposed layouts in terms of entering rate.

\begin{tabular}{|c|c|c|}
\hline & Current & Proposed \\
\hline Entering rate & 0.39 & 0.45 \\
\hline
\end{tabular}

Figure 4 shows the experimental result when the simulation and optimization were executed with the policy fixing the store position, which has the largest number of customers to be entered in descending order. The proposed method was repeated 24 times and the simulations were executed 5 trials in the each time. The optimization problem is solved using the solver named 'CPLEX12.5' by IBM.

Table 1 shows the comparison results between current and the proposed layouts in terms of entering rate. The entering rate $e r$ is calculated by $e r=v / p$, where $v$ represents the total number of customers entered into shops and $p$ means the total number of customers coming through the underground shopping street. The entering rate increases when the number of customer increases, who enters the shops as the result of achieving maximal utilities due to the layout change. The results show that the proposed method obtains the higher value of entering rate than that of current layout. The obtained layout by the proposed model is shown in Figure 4. Comparing the current layout shown in Figure 3 and the obtained layout shown in Figure 4, it can be observed that all the three categories of stores were arranged on the streets along passers' ways in a balanced manner in the obtained layout. The stores with same categories are not arranged on one or specific sides. In particular the category of restaurant stores which have higher entering rates are arranged with widely dispersed, so that it can lead the high total entering rate to be obtained.

\section{Conclusion}

This paper proposed a layout design method by integration of multi-agent based simulation and optimization. The method was incorporated into the layout design for underground shopping streets considering passengers' flow and applied to the computer experiments. Comparison results with the current layout of the store locations re- 
vealed the effectiveness of the proposed method. Applying on a larger scale and reducing the computation time can be pointed out as the further steps of the study.

\section{References}

1. Kochhar, J.S., Heragu, S.S.: Facility Layout Design in A Changing Environment, International Journal of Production Research, 37 (11), 2429-2446 (1999).

2. Muther, R.: Systematic Layout Planning, 2nd ed., Cahners Books (1973).

3. Hillier, F.S., Connors, M.M.: Quadratic Assignment Problem Algorithms and the Location of Indivisible Facilities, Management Science, 13(1), $42-57$ (1966).

4. Castell, C.M.L., Lakshmanan, R., Skilling, J.M.: Optimisation of Process Plant Layout Using Genetic Algorithms, Computers and Chemical Engineering, 22(1), 993-996 (1998).

5. Kochhar, J.S., Foster, B.T., Heragu, S.S.: A Genetic Algorithm for the Unequal Area Facility Layout Problem, Computers and Operations Research, 25(7), 583-594 (1998).

6. Andradottir, S.: A Review of Simulation Optimization Techniques, Proc. of the 1998 Winter Simulation Conference 1, 151-158 (1998).

7. Fu, M.C.: Optimization for Simulation: Theory vs. Practice, INFORMS Journal on Computing, 14(3), 192-215 (2002).

8. Kishimoto, A., Takahashi, T., Takahashi, M., Yamada, T., Tsuda, K., Terano, T.: An Agent Simulator for Analyzing Consumer Behaviors and Sales Promotion in a Retail Store (in Japanese), The 23rd Annual Conference of the Japanese Society for Artificial Intelligence, 2P2-2 (2009).

9. Moriya, M., Kashihara, S., Yoshimura, H., Yokota, T., Sakata, K: Investigation of Crowd Flow and the Number of People Staying in the Diamond Underground Street and its Influence on the Crowd Flow in the Adjacent Areas (in Japanese), Annual report of the division of Kinki Region of Architectural Institute of Japan, 37, 121-124 (1999). 